\title{
HUBUNGAN MOTIVASI INTRINSIK TERHADAP PELAKSANAAN PEMBELAJARAN LANGSUNG DI FAKULTAS KEDOKTERAN HALU OLEO UNIVERSITAS KENDARI
}

\author{
Ashaeryanto $^{1}$, Satrio Wicaksono ${ }^{2}$, Juminten Saimin $^{3}$, Rezki Fitrianti ${ }^{3}$ \\ 1,2 Department of Biomedical, Faculty of Medicine, Universitas Halu Oleo, Kendari, Indonesia \\ ${ }^{3}$ Department of Obstetrics and Gynecology, Faculty of Medicine, Universitas Halu Oleo, Kendari, Indonesia \\ ${ }^{4}$ Medical student, Faculty of Medicine, Universitas Halu Oleo, Kendari, Indonesia
}

\begin{abstract}
Self-Directed Learning (SDL) is a student-centered learning in which the process and experience of learning are individually regulated and controlled by the student. The implementation of SDL is an interaction of several aspects, including self-motivation, self-control, and self-monitoring skills. Students with strong motivation in the learning process will have more consistency in implementing the SDL. Inner self-motivation will give better impacts than that obtained from the outside. This study aimed to analyze the correlation of intrinsic motivation to SDL implementation in the Faculty of Medicine of Halu Oleo University. The study was quantitative research using a cross-sectional design. Subjects were 91 sophomores of the Faculty of Medicine of Halu Oleo University (UHO). Data were collected using a total sampling method. SDL implementation and intrinsic motivation were measured using SelfDirected Learning Readiness Scale (SDLRS) and Intrinsic Motivation Inventory (IMI) questionnaires, respectively. Data were statistically analyzed using Pearson's correlation. Second-year of medical students of UHO showed a high intrinsic motivation and SDL implementation. Students with high intrinsic motivation were found to apply high implementation of SDL. Moreover, students with moderate intrinsic motivation also showed high implementation of SDL. There is a significant correlation between intrinsic motivation to SDL implementation among medical students of UHO. Further research is required to investigate other factors that affect the SDL implementation of medical students.
\end{abstract}

\begin{abstract}
Abstrak
Self-Directed Learning (SDL) adalah pembelajaran yang berpusat pada siswa di mana proses dan pengalaman belajar secara individual diatur dan dikendalikan oleh siswa. Implementasi SDL merupakan interaksi dari beberapa aspek, termasuk motivasi diri, kontrol diri, dan keterampilan pemantauan diri. Siswa dengan motivasi yang kuat dalam proses pembelajaran akan lebih konsisten dalam menerapkan SDL. Motivasi diri batiniah akan memberi dampak lebih baik daripada yang didapat dari luar. Penelitian ini bertujuan untuk menganalisis hubungan motivasi intrinsik dengan implementasi SDL di Fakultas Kedokteran Universitas Halu Oleo. Penelitian ini adalah penelitian kuantitatif dengan menggunakan desain cross-sectional. Subjek penelitian adalah 91 mahasiswa Fakultas Kedokteran Universitas Halu Oleo (UHO). Data dikumpulkan dengan menggunakan metode total sampling. Implementasi SDL dan motivasi intrinsik diukur menggunakan Self-Directed Learning Readiness Scale (SDLRS) dan kuesioner Intrinsic Motivation Inventory (IMI). Data dianalisis secara statistik menggunakan korelasi Pearson. Mahasiswa kedokteran UHO tahun kedua menunjukkan motivasi intrinsik dan implementasi SDL yang tinggi. Siswa dengan motivasi intrinsik tinggi ditemukan menerapkan penerapan SDL yang tinggi. Selain itu, siswa dengan motivasi intrinsik moderat juga menunjukkan implementasi SDL yang tinggi. Ada hubungan yang signifikan antara motivasi intrinsik dengan implementasi SDL di antara mahasiswa kedokteran UHO. Penelitian lebih lanjut diperlukan untuk menyelidiki faktor-faktor lain yang mempengaruhi implementasi SDL mahasiswa kedokteran.
\end{abstract}

\section{PENDAHULUAN}

Self Directed Learning (SDL) adalah pembelajaran yang berpusat pada peserta didik dimana proses dan pengalaman belajar diatur dan dikontrol oleh peserta didik sendiri.. Penerapan SDL merupakan interaksi beberapa aspek yaitu motivasi diri, pengaturan diri, dan keterampilan memonitor diri. Motivasi berperan dalam menerapkan SDL sehingga mahasiswa yang mempunyai motivasi kuat dalam proses 
pembelajaran akan lebih konsisten dalam menerapkan SDL. Pelaksanaan SDL dapat diterapkan dalam pendekatan belajar Problem Based Learning (PBL) (Gunanegara dkk, 2017).

Pembelajaran berbasis masalah adalah sebuah cara memanfaatkan masalah untuk menimbulkan motivasi belajar. Masalah dapat mendorong keseriusan, inquiry, dan berfikir dengan cara yang bermakna.

Motivasi belajar adalah kecenderungan mahasiswa dalam belajar yang didorong oleh hasrat untuk mencapai hasil belajar sebaik mungkin yang terdiri atas motivasi intrinsik dan ekstrinsik. Motivasi intrinsik melibatkan proses kognitif mahasiswa. Mahasiswa mengontrol sendiri tujuan pembelajaran, merencanakan pembelajaran dan memantau pelajarannya. Motivasi intrinsik dapat meningkatkan efektivitas kelompok diskusi dalam PBL dimana motivasi belajar yang timbul dari dalam diri mahasiswa, akan jauh lebih baik daripada motivasi yang muncul dari luar. Penerapan pembelajaran PBL di Indonesia dengan pemusatan pada keaktifan mahasiswa telah membuktikan bahwa pemahaman mahasiswa menjadi lebih baik dan lebih mandiri (Kurdi, 2009).

Fakultas Kedokteran UHO, sebagai salah satu institusi kedokteran di Indonesia yang telah menerapkan metode pembelajaran dengan pendekatan PBL terus melaksanakan evaluasi terhadap pencapaian pembelajaran yang diharapkan. Hal yang dilakukan diantaranya menyiapkan segala fasilitas yang menunjang pembelajaran seperti tersedianya perpustakaan yang lengkap dan fasiltas internet yang bisa diakses setiap saat oleh mahasiswa sehingga mahasiswa akan lebih mudah menjalankan proses pembelajaran. Pada kenyataannya, perilaku SDL di Fakultas Kedokteran UHO belum terbentuk secara maksimal. Hal tersebut bisa dilihat pada beberapa parameter, diantaranya melalui studi observasiobal terhadap kunjungan perpustakaan Fakultas Kedokteran Universitas Halu Oleo pada periode Agustus 2017 - Maret 2018 didapatkan jumlah kunjungan hanya mencapai 361 kunjungan, padahal jumlah mahasiswa kedokteran UHO mencapai 700 mahasiswa. Prestasi belajar yang dicapai oleh mahasiswa kedokteran UHO dengan metode PBL belum menunjukkan pencapaian yang baik. Hal ini bisa dilihat pada hasil belajar mahasiswa tahun pertama yang menunjukkan bahwa terdapat $72 \%$ mahasiswa yang memperoleh nilai kurang memuaskan pada mata kuliah Mekanisme Dasar Penyakit dan terdapat $45 \%$ mahasiswa yang memperoleh nilai kurang memuaskan pada mata kuliah yang diambil di semester dua.

Atas dasar tersebut maka peneliti bermaksud untuk melakukan penelitian tentang Hubungan motivasi intrinsik terhadap penerapan SDL di Fakultas Kedokteran UHO.

\section{METODE}

Jenis penelitian ini merupakan penelitian kuantitatif dengan menggunakan rancangan potong lintang untuk menganalisis hubungan motivasi intrinsik terhadap penerapan SDL di Fakultas Kedokteran Universitas Halu Oleo Kendari, Sulawesi Tenggara. Penelitian ini dilaksanakan pada bulan Juni hingga Juli 2018 di Fakultas Kedokteran Universitas Halu Oleo. Subjek penelitian adalah mahasiswa tahapan sarjana tahun ke dua di Fakultas Kedokteran Universitas Halu Oleo (UHO) Kendari yang berjumlah 91 mahasiswa. Variabel terikat penelitian ini adalah penerapan SDL sedangkan variable bebas adalah motivasi intrinsik. Pengambilan sampel menggunakan metode total sampling dengan menggunakan kuesioner Self-Directed Learning Readiness Scale (SDLRS) yang dikembangkan oleh Fisher untuk mengukur penerapan SDL dan kuesioner Intrinsic Motivation Inventory (IMI) untuk mengukur motivasi intrinsik. Kuesioner yang digunakan, sebelumnya telah dilakukan uji validitas dan reliabilitas.

Kuesioner diisi oleh responden, dengan terlebih dahulu peneliti menjelasakan tentang tujuan dan manfaat penelitian serta 
cara pengisian kuesioner. Responden terlebih dahulu menandatangani informed consent. Pengumpulan kuesioner dilakukan setelah responden mengisi kuesioner kemudian dilakukan pengolahan data. Analisis data dengan menggunakan uji statistik korelasi pearson dengan program komputer SPSS versi 16.0. Analisis univariat dilakukan untuk menjelaskan atau mendeskripsikan karakteristik dari motivasi intrinsik dan penerapan Self Directed Learning. Analisis bivariat dilakukan untuk menganalisis hubungan antara motivasi intrinsik terhadap penerapan Self Directed Learning. Penelitian ini telah mendapatkan persetujuan dari Komisi Etik Penelitian Kesehatan Lembaga Penelitian dan Pengabdian pada Masyarakat Universitas Halu Oleo.

\section{HASIL DAN PEMBAHASAN}

\section{Analisis Univariat}

Tabel 1. Karakteristik responden berdasarkan jenis kelamin, motivasi intrinsik dan penerapan Self Directed Learning (SDL)

\begin{tabular}{lcc}
\hline & Jumlah (n) & Presentase (\%) \\
\hline Jenis kelamin & 30 & 33 \\
Laki-laki & 61 & 67 \\
Perempuan & & \\
\hline Motivasi intrinsik & 68 & 74,7 \\
Tinggi & 23 & 25,3 \\
Sedang & 0 & 0 \\
Rendah & & \\
\hline Penerapan self directed learning & 63 & 69,2 \\
Tinggi & 28 & 30,8 \\
Sedang & 0 & 0 \\
Rendah & 91 & 100 \\
\hline Total & & \\
\hline S
\end{tabular}

Sumber: Data Primer, 2018

Pada tabel 1 menunjukkan bahwa distribusi responden berdasarkan jenis kelamin dengan presentase tertinggi terdapat pada jenis kelamin perempuan yaitu 61 orang (67\%), sedangkan jenis kelamin laki-laki sebanyak 30 orang $(33 \%)$. Penilaian terhadap motivasi intrinsik didapatkan mahasiswa yang memiliki motivasi intrinsik tinggi sebanyak 68 orang $(74,7 \%)$ dan terendah yaitu mahasiswa yang memiliki motivasi intrinsik sedang sebanyak 23 orang $(25,3 \%)$. Pada penilaian SDL didapatkan mahasiswa yang memiliki kemampuan SDL tinggi sebanyak 63 orang $(69,2 \%)$ dan terendah yaitu mahasiswa yang memiliki kemampuan SDL sedang sebanyak 28 orang (30,8\%).

Tabel 2. Distribusi motivasi intrinsik dan penerapan SDL berdasarkan jenis kelamin

\begin{tabular}{lcccc}
\hline & \multicolumn{4}{c}{ Jenis Kelamin } \\
\cline { 2 - 5 } & \multicolumn{3}{c}{ Laki-laki } & \multicolumn{3}{c}{ Perempuan } \\
\cline { 2 - 5 } & $\mathrm{N}$ & $\%$ & $\mathrm{~N}$ & $\%$ \\
\hline Motivasi intrinsik & 22 & 73,3 & 46 & 75,4 \\
Tinggi & 8 & 26,7 & 15 & 24,6 \\
Sedang & 0 & 0 & 0 & 0 \\
Rendah & & &
\end{tabular}




\begin{tabular}{lcccc}
\hline Penerapan self directed learning & & & & \\
Tinggi & 21 & 70,0 & 42 & 68,9 \\
Sedang & 9 & 30,0 & 19 & 31,1 \\
Rendah & 0 & 0 & 0 & 0 \\
\hline Total & 30 & 100 & 61 & 100 \\
\hline
\end{tabular}

Sumber : Data Primer, 2018

Distribusi berdasarkan motivasi intrinsik untuk mahasiswa yang berjenis kelamin lakilaki terdapat 22 mahasiswa $(73,3 \%)$ yang memiliki motivasi intrinsik tinggi dan 8 mahasiswa $(26,7 \%)$ yang memiliki motivasi sedang. Sedangkan mahasiswa yang berjenis kelamin perempuan terdapat 46 mahasiswa $(75,4 \%)$ yang memiliki motivasi intrinsik tinggi dan 15 mahasiswa $(24,6 \%)$ yang memiliki motivasi intrinsik sedang.
Distribusi berdasarkan penerapan SDL untuk mahasiswa berjenis kelamin laki-laki terdapat 21 mahasiswa (70\%) yang memiliki penerapan SDL tinggi dan 9 mahasiswa (30\%) yang memiliki penerapan SDL sedang. Sedangkan mahasiswa yang berjenis kelamin perempuan terdapat 42 mahasiswa $(68,9 \%)$ yang memiliki penerapan SDL tinggi dan 19 mahasiswa $(31,1 \%)$ yang memiliki penerapan SDL sedang.

Tabel 3. Distribusi responden berdasarkan variabel penelitian

\begin{tabular}{lcccccc}
\hline & \multicolumn{7}{c}{ Penerapan self directed learning } \\
\cline { 2 - 8 } & \multicolumn{2}{c}{ Tinggi } & \multicolumn{2}{c}{ Sedang } & Rendah \\
\cline { 2 - 8 } & $\mathrm{N}$ & $\%$ & $\mathrm{~N}$ & $\%$ & $\mathrm{~N}$ & $\%$ \\
\hline Motivasi intrinsic & 49 & 77,8 & 19 & 67,9 & 0 & 0 \\
Tinggi & 14 & 22,2 & 9 & 32,1 & 0 & 0 \\
Sedang & 0 & 0 & 0 & 0 & 0 & 0 \\
Rendah & 63 & 100 & 28 & 100 & 0 & 0 \\
\hline Total & & & & & & \\
\hline Sotal
\end{tabular}

Sumber : Data Primer, 2018

Distribusi responden berdasarkan motivasi intrinsik terhadap penerapan SDL terdapat 49 mahasiswa $(77,8 \%)$ memiliki motivasi intrinsik dan penerapan SDL tinggi sedang terdapat 19 mahasiswa $(67,9 \%)$ yang memiliki motivasi intrinsik tinggi dan penerapan SDL sedang. Mahasiswa dengan motivasi intrinsik sedang dan memiliki penerapan SDL tinggi sebanyak 14 mahasiswa $(22,2 \%)$ sedangkan mahasiswa yang memiliki motivasi intrinsik dan penerapan SDL sedang terdapat 9 mahasiswa $(32,1 \%$

\section{Analisis Bivariat}

Analisis bivariat pada penelitian ini menunjukkan analisis hubungan motivasi intrinsik dengan penerapan SDL pada mahasiswa Fakultas Kedokteran Universitas Halu Oleo

Tabel 4. Analisis hubungan motivasi intrinsik dengan penerapan self directed learning

\begin{tabular}{|c|c|c|c|c|c|c|c|c|c|c|}
\hline \multirow{3}{*}{$\begin{array}{l}\text { Motivasi } \\
\text { Intrinsik }\end{array}$} & \multicolumn{8}{|c|}{ Penerapan Self Directed Learning } & \multirow{3}{*}{ Pearson } & \multirow{3}{*}{$\begin{array}{c}\text { Koefisien korelasi } \\
\text { (r) }\end{array}$} \\
\hline & \multicolumn{2}{|c|}{ Tinggi } & \multicolumn{2}{|c|}{ Sedang } & \multicolumn{2}{|c|}{ Rendah } & \multicolumn{2}{|r|}{ Total } & & \\
\hline & $\mathrm{N}$ & $\%$ & $\mathrm{~N}$ & $\%$ & $\mathrm{~N}$ & $\%$ & $\mathrm{~N}$ & $\%$ & & \\
\hline Tinggi & 49 & 77,8 & 19 & 67,9 & 0 & 0 & 68 & 74,7 & & 0,276 \\
\hline
\end{tabular}




\begin{tabular}{lccccccccc}
\hline Sedang & 14 & 22,2 & 9 & 32,1 & 0 & 0 & 23 & 25,3 & $\begin{array}{l}\text { P-Value } \\
\mathbf{0 , 0 0 8}\end{array}$ \\
\hline Total & 63 & 69,2 & 28 & 30,8 & 0 & 0 & 91 & 100 & \\
\hline
\end{tabular}

Sumber: Data Primer, 2018

Tabel 4 menunjukkan hasil analisis hubungan motivasi intrinsik dengan penerapan SDL didapatkan dari 91 responden terdapat 49 mahasiswa $(77,8 \%)$ memiliki motivasi intrinsik dan penerapan SDL tinggi dan terdapat 19 mahasiswa $(67,9 \%)$ yang memiliki motivasi intrinsik tinggi sedangkan penerapan SDL dalam kategori sedang. Mahasiswa dengan motivasi intrinsik sedang dan memiliki penerapan SDL tinggi sebanyak 14 mahasiswa $(22,2 \%)$, sedangkan mahasiswa yang memiliki motivasi intrinsik dan penerapan SDL sedang terdapat 9 mahasiswa $(32,1 \%)$.

Hasil uji statistik didapatkan nilai pvalue 0,008 yang berarti lebih kecil daripada 0,05 . Hal ini menunjukkan bahwa terdapat hubungan yang signifikan antara motivasi intrinsik dengan penerapan SDL, sedangkan nilai koefisien korelasi menunjukkan hubungan korelasi yang lemah karena nilai r yaitu 0,276 . Nilai koefisien korelasi 0,276 bertandakan positif, yang menunjukkan bahwa arah hubungan antara variabel ini adalah positif, berarti semakin tinggi motivasi intrinsik maka semakin meningkatkan kemampuan SDL pada mahasiswa.

\section{Hubungan Antara Motivasi Intrinsik dengan Penerapan Self Directed Learning (SDL)}

Berdasarkan hasil analisis menunjukkan bahwa motivasi intrinsik dan penerapan SDL berdasarkan jenis kelamin didapatkan mahasiswa dengan jenis kelamin perempuan lebih banyak memiliki motivasi intrinsik dan penerapan SDL tinggi dibandingkan dengan mahasiswa yang berjenis kelamin laki-laki. Hal ini sejalan dengan hasil penelitian Adilla dkk (2016) didapatkan bahwa mahasiswa yang berjenis kelamin perempuan memiliki motivasi belajar lebih baik dibandingkan dengan laki-laki. Faktor yang mempengaruhi mahasiswa mempunyai motivasi baik yaitu mahasiswa mempunyai tujuan yang harus dicapai selama mengikuti perkuliahan sehingga mahasiswa mempunyai dorongan dan motivasi untuk mencapai tujuan tersebut.

Berdasarkan hasil analisis uji korelasi pearson menunjukkan bahwa mahasiswa yang memiliki motivasi intrinsik dan penerapan SDL tinggi lebih banyak dibandingkan mahasiswa yang memiliki motivasi intrinsik tinggi sedangkan penerapan SDL sedang, mahasiswa yang memiliki motivasi intrinsik sedang dan memiliki penerapan SDL yang juga sedang, serta mahasiswa yang memiliki motivasi intrinsik sedang dan penerapan SDL tinggi. Faktor internal yang mempengaruhi kurangnya motivasi belajar yaitu minat untuk belajar karena mahasiswa yang tidak mempunyai minat pada suatu materi cenderung untuk tidak memiliki motivasi dalam belajar. Kedua yaitu konsentrasi, dalam belajar mahasiswa memerlukan konsentrasi untuk menerima suatu informasi. Mahasiswa yang sulit untuk memusatkan konsentrasinya maka akan enggan untuk belajar. Ketiga yaitu kepercayaan diri, mahasiswa yang memiliki kurang rasa percaya diri dalam belajar maka akan kesulitan menyerap materi (Dalyono dalam Fauziyatun, 2014). Faktor yang mempengaruhi rendahnya SDL yaitu kurangnya belajar mahasiswa secara mandiri karena pemahaman terhadap suatu materi yang masih rendah sehingga mahasiswa sulit untuk memecahkan suatu masalah yang diberikan serta kurangnya sifat keingintahuan yang tinggi terhadap suatu materi.

Hasil penelitian ini sejalan dengan penelitian Kurniawan (2014) terdapat hubungan antara motivasi belajar terhadap 
kemandirian belajar siswa dengan tingkat korelasi lemah yaitu $r=0,374$. Hasil penelitian ini juga didukung oleh penelitian Darmayanti dkk (2015) didapatkan hubungan yang signifikan antara motivasi belajar dengan kemandirian belajar pada mahasiswa Universitas Medan Area, namun terdapat perbedaan nilai korelasi (r) yaitu sebesar 0,606 hal ini dikategorikan dalam korelasi kuat sedangkan dalam penelitian ini didapatkan nilai korelasi yang lemah yaitu $r$ $=0,276$.

\section{KESIMPULAN DAN SARAN}

Simpulan pada penelitian ini menunjukkan bahwa terdapat hubungan yang signifikan antara motivasi intrinsik dengan penerapan Self Directed Learning (SDL) pada mahasiswa Fakultas Kedokteran Universitas Halu Oleo dengan korelasi hubungan antara variabel dalam kategori lemah.

Diharapkan hasil penelitian ini dapat dijadikan sebagai bahan evaluasi terhadap perilaku Self Directed Learning (SDL) di Fakultas Kedokteran Universitas Halu Oleo, dapat lebih mendorong mahasiswa untuk lebih aktif dan mandiri memanfaatkan fasiltas pembelajaran di Fakultas Kedokteran UHO serta diharapkan kepada peneliti selanjutnya dapat melakukan penelitian faktor lain yang dapat mempengaruhi self directed learning.

\section{REFERENSI}

1. Adilla, H., Haryani, W., Taadi. 2016. Motivasi dan Prestasi Belajar Mahasiswa Keperawatan Gigi Poltekkes Kemenkes Yogyakarta. Jurnal Gigi dan Mulut 3(2) : 90-91.

2. Amir, Z. 2013. Perspektif Gender Dalam Pembelajaran Matematika. Universitas Pendidikan Indonesia Bandung 12(1) : 18.

3. Anwar. A.I., Prabandari, Y.S., Emilia, O. 2013. Motivasi Dan Strategi Belajar Siswa Dalam Pendidikan Pembelajaran Berbasis Masalah Dan Collaborative
Learning Di Fakultas Kedokteran Gigi Universitas Hasanuddin. Jurnal Pendidikan Kedokteran Indonesia 2(3): 233.

4. Darmayanti, N., Siregar, M., Harahap, P. 2015. Hubungan antara Motivasi Belajar dan Kemandirian Belajar Pada Mahasiswa Universitas Medan Area. Jurnal Psikologia 10(2) : 18-24.

5. Fauziyatun, N. 2014. Faktor-Faktor yang Melatarbelakangi Rendahnya Motivasi Belajar Siswa Kelas IX SMP Negeri 22 Semarang Tahun Ajaran 2013/2014. Skripsi. Universitas Negeri Semarang. Semarang.

6. Ferlina, T.R. 2014. Hubungan Persepsi Penerapan Pembelajaran Metode Tutorial, dengan Kemandirian Belajar Mahasiswa Semester II di Stikes Aisyiyah Yogyakarta Tahun 2014. Skripsi. Stikes Aisyiyah Yogyakarta.

7. Gunanegara, R.F., Wahid, M.H., Widyahening, I.S. 2017. Comparison Of Students' Characteristics, SelfMotivation, And Readiness Of SelfDirected Learning Implementation Among Medical Students At Maranatha Christian University. Journal of Medicine and Health 1(5) : 458-460.

8. Konsil Kedokteran Indonesia (KKI). 2012. Standar Kompetensi Dokter Indonesia. Ed.2. Penerbit Konsil Kedokteran Indonesia. Jakarta.

9. Kurdi, F.N. 2009. Penerapan Student Centered Learning Dari Teacher Centered Learning Mata Ajar Ilmu Kesehatan Pada Program Studi Penjaskes. Jurnal Forum Kependidikan 28(2) : 108

10. Kurniawan, D. 2014. Hubungan Motivasi Belajar Terhadap Kemandirian Belajar Siswa Kelas Xi Pada Kompetensi Mengidentifikasi Sistem Pengapian Dan Komponennya Program Studi Keahlian Teknik Otomotif Smk Tamansiswa Yogyakarta Tahun Ajaran 2013/2014. Skripsi. Universitas Negeri Yogyakarta. Yogyakarta. 
11. Lisiswanti, R., Saputra, O. 2015. Faktor-Faktor yang Mempengaruhi Ketertarikan Mahasiswa Kuliah Dalam Kelas Besar. Jurnal Kedokteran Unila $5(9): 117$.

12. Pelawi, H.S., Sinulingga, K. 2016. Pengaruh Model Problem Based Learning dan Motivasi Belajar Terhadap Hasil Belajar Siswa Di Kelas X SMA Swasta Sinar Husni. Jurnal Unimed 5(1) : 33 .
13. Pioh, V., Mewo, Y., Berhimpon, S. 2016. Efektivitas kelompok diskusi tutorial problem based learning di Fakultas Kedokteran Universitas Sam Ratulangi. Jurnal e-Biomedik 4(1) : 7-9. 14. Ranti, M.G., Budiarti, I., Trisna, B.N. 2017. Pengaruh Kemandirian Belajar (Self Regulated Learning) Tarhadap Hasil Belajar Mahasiswa Pada Mata Kuliah Struktur Aljabar. Jurnal Pendidikan Matematika 3(1) : 75 